\title{
Amblyopia and Strabismus Questionnaire (A\&SQ): clinical validation in a historic cohort
}

\author{
Elizabeth S. van de Graaf • Geertje W. van der Sterre • \\ Hanneke van Kempen-du Saar • Brigitte Simonsz • \\ Caspar W. N. Looman • Huib J. Simonsz
}

Received: 6 October 2006 /Revised: 20 March 2007 / Accepted: 5 April 2007 / Published online: 5 June 2007

(C) Springer-Verlag 2007

\begin{abstract}
Background We recently developed the Amblyopia \& Strabismus Questionnaire (A\&SQ) to assess the quality of life in amblyopia and/or strabismus patients, and evaluated its content and criterion validity. The A\&SQ was now validated clinically by correlating its outcome with past and current orthoptic parameters in a historic cohort of amblyopia and/or strabismus patients.

Methods The cohort was derived from all 471 patients who were treated by occlusion therapy in the Waterland Hospital in Purmerend between 1968 and 1974 and born between 1962 and 1972. All children with insufficient visual acuity from the Waterland area had been referred to a single ophthalmologist and orthoptist. Of these, 203 were traced, and 174 filled out the A\&SQ. In 137 of these, binocular vision, visual acuity, and angle of strabismus were reassessed 30-35 years after occlusion therapy. These clinical parameters were correlated with the five A\&SQ
\end{abstract}

The study was not sponsored.

E. S. van de Graaf • G. W. van der Sterre • B. Simonsz •

H. J. Simonsz $(\square)$

Department of Ophthalmology, Erasmus MC,

University Medical Center Rotterdam,

P.O. Box 2040, NL-3000 CA Rotterdam, The Netherlands

e-mail: Simonsz@compuserve.com

C. W. N. Looman

Department of Public Health, Erasmus MC,

University Medical Center Rotterdam,

P.O. Box 2040, NL-3000 CA Rotterdam, The Netherlands

H. van Kempen-du Saar

Department of Ophthalmology, Waterland Hospital,

P.O. Box 250, NL-1440 AG Purmerend, The Netherlands domains: "distance estimation", "visual disorientation", "fear of losing the better eye", "diplopia", and "social contact and cosmetic problems".

Results The current acuity at distance of the amblyopic eye and reading acuity of the amblyopic eye correlated significantly with all five A\&SQ domains (significance level $P=0.01-P=0.05$ ). Weaker correlations were found for binocularity. In spite of the expectation that stereopsis should strongly correlate with the domain "distance estimation", and angle of strabismus with the domain "social contact and cosmetic problems", the acuity of the amblyopic eye was the overall dominant parameter.

Conclusions The adult acuity of the amblyopic eye seems the most important clinical determinant for quality of life in amblyopia and/or strabismus patients, even in domains of distance estimation, visual disorientation, and social contact and cosmetic problems, although intermediate determinants cannot be excluded.

Keywords Amblyopia - Quality of life questionnaire . Validity

\section{Introduction}

Amblyopia screening and treatment firstly prevents the costs of insufficiently treated amblyopia patients who lose the function of their better eye later in life. Cost-effectiveness evaluations of screening and treatment should also consider amblyopia patients who are insufficiently treated but retain their better eye. They experience only a minor decrease in the quality of life, but the condition occurs much more frequently, in approx. $1 \%$ of the population [1]. Rahi recently could not detect a functionally or socially significant decrease in the quality of life of amblyopes as 
based on gross outcomes of quality of life, like educational achievement, employment, and socioeconomic achievement [2]. Such decrease can, however, be detected at the level of daily functional restrictions in amblyopia patients.

We have therefore designed a questionnaire-analogous to the National Eye Institute Visual Function Questionnaire-25 [3] (VFQ-25) [4] - specific for amblyopia and strabismus in order to assess the decrease in quality of life of such patients, the Amblyopia and Strabismus Questionnaire (A\&SQ) [5]. The A\&SQ is similar to the VFQ-25 in design, format and methods of development and of scoring. The A\&SQ contains twenty-six questions that were formulated within five domains: "distance estimation", "visual disorientation", "fear of losing the better eye", "social contact and cosmetic problems" and "diplopia". The A\&SQ has been translated into English [6]. Content validity and criterion validity have been previously evaluated by comparison with two existing and validated quality of life questionnaires, the VFQ-25 and the Short-Form 12 Health Survey (SF-12) [5]. In that study, 53 healthy controls, 68 outpatients and a historic cohort of 174 patients had filled out the questionnaires. Construct validity of the A\&SQ has been demonstrated by factor analysis [7].

The clinical validity of the A\&SQ was now ascertained by correlating the A\&SQ domains to past and current orthoptic parameters of amblyopia patients who had been treated by occlusion therapy $30-35$ years ago. These adult amblyopia patients were recruited using the original patient charts kept by the orthoptist who had treated them at childhood more than 30 years ago. Population-based vision screening was operational at the time, and all children with insufficient visual acuity from the entire region of Waterland had been referred to a single ophthalmologist and orthoptist.

In 2003, we re-examined the amblyopia patients to correlate the A\&SQ domains to past and current orthoptic parameters.

We expected binocular vision to be correlated to the domain "distance estimation" as well as to the domain "visual disorientation", and the angle of strabismus to the domain "social contact and cosmetic problems". Contrary to this, the current visual acuity of the amblyopic eye was found to be the overall dominating parameter for all five A\&SQ domains.

\section{Methods}

The study was approved by the Medical Ethical Committee of the Erasmus MC and the Medical Ethical Committee of the Waterland Hospital, and was performed according to the standards of the 1964 Declaration of Helsinki.

\section{Patients}

The historic cohort was derived from all 1250 subjects, mostly children, who had consulted the orthoptic outpatient clinic of the Waterland Hospital in Purmerend between 1968 and 1974. The hospital served during this period the entire region of Waterland, a rural area north of Amsterdam, bordered on its eastern side by the IJsselmeer. It contains one town-Purmerend - and eight villages. There was little migration in this area across communities.

The original orthoptic charts of these 1250 patients had been kept since 1968 by the orthoptist (HvK). 471 of these patients were children who had been treated for amblyopia with occlusion therapy (Fig. 1). They were born between 1962 and 1972. Of the 471 occluded children, 203 could be traced and were sent the questionnaires; 2 of the 203 patients had died in the meantime. 268 of the 471 patients treated with occlusion therapy could not be traced. In 133 cases, these patients had no known phone numbers. Ninetynine patients could not be reached on the given phone number even after repeatedly trying to reach them. For 36 patients, the given phone numbers were not longer in service. Of the traced 203 patients, 174 filled out and returned the SF-12, the VFQ-25, and the A\&SQ [5], whereas the questionnaires for four patients were sent to an old address.

137 patients of the historic cohort who had filled out the questionnaires gave their informed consent to undergo an orthoptic examination. Thirty-seven patients who had filled out the questionnaires $(N=174)$ did not undergo the examination. Ten could not be reached, nine refused to participate, seven did not meet the appointment for the examination, eight were unable to attend the examination because they were hospitalized, abroad or living too far from Purmerend, and four had omitted their name on the filled-out questionnaires.

Orthoptic examination

The following data from the examination 30 years ago, noted on the orthoptic charts, were used: visual acuity at distance of both eyes at the start and end of the treatment, the degree of binocular vision and angle of strabismus. The criteria that the orthoptist had employed to diagnose amblyopia at the start of the occlusion therapy were, in preverbal children, the inability to hold fixation with one eye and, in verbal children, a difference $>1 \log$ MAR line between the visual acuities of both eyes.

In the current orthoptic re-examination, binocular vision was examined with Bagolini glasses at distance $(6 \mathrm{~m})$ and near $(30 \mathrm{~cm})$ and with tests for stereopsis: Titmus test (fly, animals and circles), Lang II test, and TNO test. Visual acuity was measured (at $6 \mathrm{~m}$ ) by a projector and optotypes. A Dutch 
Fig. 1 Flowchart showing the number of patients (children) that had been occluded, been traced at adulthood, had filled out the questionnaires and had undergone the orthoptic examination in 2003

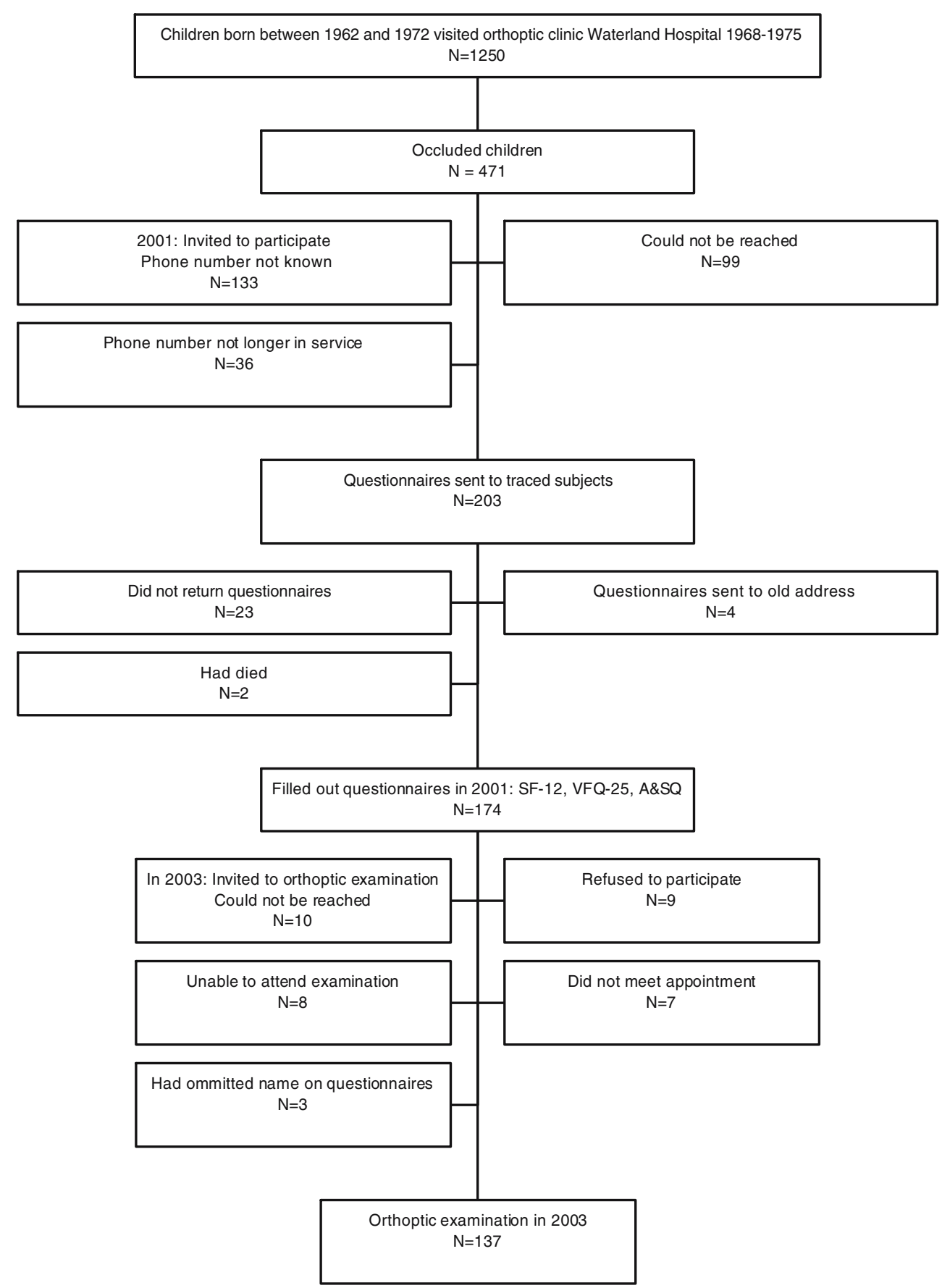

reading test (hereafter abbreviated: DRT) (Medical Workshop, the Netherlands) was performed at near $(0.35 \mathrm{~m})$ with the text at five sizes: $\mathrm{D}=0.5 ; \mathrm{D}=0.8 ; \mathrm{D}=1 ; \mathrm{D}=1.25 ; \mathrm{D}=2$ with $\mathrm{D}=1$ lettering equivalent to newspaper print. The current angle of strabismus was measured by the simultaneous and alternating prism covertests during fixation at distance $(6 \mathrm{~m})$ and at near $(30 \mathrm{~cm})$. Latent nystagmus and dissociated vertical divergence (DVD) were also noted, if present. Retinoscopy was performed without cycloplegia, but in the dark, followed by subjective refraction to obtain best corrected visual acuity.
Anisometropia was defined as a difference between the spherical equivalences of both eyes larger than $1 \mathrm{D}$.

The correlation $(r)$ between the clinical parameters (visual acuity at distance of both eyes, degree of binocular vision and angle of strabismus) and the five A\&SQ domains was measured by the Pearson correlation test (two-tailed). These correlations could be determined accordingly because the continuous parameters had a more or less normal distribution. The level of significance was divided into * $(P=0.01-$ $P=0.05$ and $* *(P<0.01)$. The correlations between the 


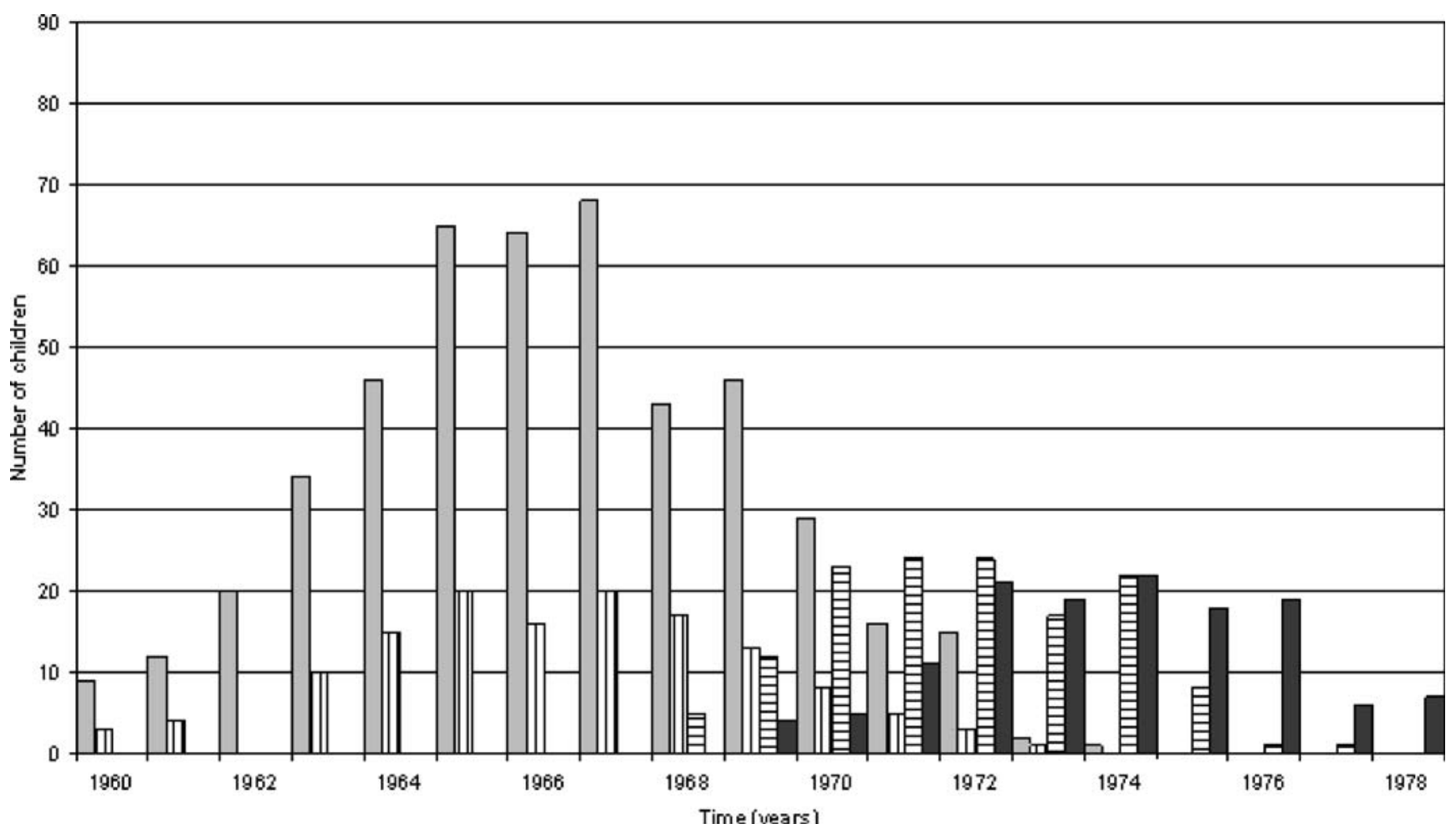

Fig. 2 The number of patients (children) per year of birth of the 471 amblyopic patients occluded between 1968 and 1975 in the Waterland Hospital and the 137 re-examined patients are indicated by gray bars

and vertically striated bars, respectively. In addition, time (years) of start and end of occlusion treatment of the 137 re-examined patients are indicated by horizontally striated bars and black bars respectively

dichotomous clinical parameters (nasal fixation, latent nystagmus and anisometropia) and the A\&SQ domains were analyzed by mean score differences; level of significance was determined with the unpaired $t$-test.

\section{Results}

Demographic data

The 1250 subjects, mostly children, consulted the ophthalmologist and/or orthoptist of the hospital either on their own initiative or after referral by a child health care center or the general practitioner. Ophthalmologic care was provided between 1968 and 1975 by the sole ophthalmologist and orthoptist (HvK) practicing in the region.

We determined whether the historic cohort was representative for the entire population in the region at that time. The prevalence of amblyopia is reported to be approx. $3.25 \%$ in adults [8]. We expected a lower rate of children occluded in the historic cohort because children could have been treated elsewhere or been lost to follow-up. In order to clarify this, a comparison was made between the 471 children who had been treated by occlusion therapy by $\mathrm{HvK}$ and the local birth rates.
Of the 471 occluded children, most had been born in the years 1965, 1966, and 1967 (66, 64, and 68 respectively; 198 children in total (Fig. 2). The number of births in the years 1965, 1966 and 1967 in the region was derived from the registers of births: 1286, 1328 and 1355, 3969 children in total. The 198 children out of these 3969 children that had been occluded resulted in a prevalence of $5.0 \%$ occluded children in our historic cohort. The diagnosis of true amblyopia at the start of the occlusion therapy could in hindsight not be confirmed for 7 of the 137 patients. Accordingly, our cohort represented a prevalence of $4.8 \%$ occluded children in that region after correction for this fraction.

The group of the 137 patients had the following characteristics: mean age was 35.9 years, $>75 \%$ of patients

Table 1 Demographic data patients

\begin{tabular}{lll}
\hline$N=137$ & & \\
\hline Gender & Male & $72(52.5 \%)$ \\
& Female & $65(47.5 \%)$ \\
Age & Mean (SD) & $35.85(2.79)$ \\
Education & Primary & $30(21.9 \%)$ \\
& Secondary & $46(33.6 \%)$ \\
& Higher & $60(43.8 \%)$ \\
& Unknown & $1(0.7 \%)$ \\
\hline
\end{tabular}


Table 2 Results of orthoptic examination (acuity expressed in $\log$ MAR)

\begin{tabular}{|c|c|c|c|c|c|c|}
\hline \multirow{2}{*}{$\begin{array}{l}\text { Occlusion } 30- \\
35 \text { years ago } \\
N=137\end{array}$} & \multicolumn{2}{|c|}{$\begin{array}{l}\text { Start } \\
\text { occlusion }\end{array}$} & \multicolumn{2}{|c|}{$\begin{array}{l}\text { End } \\
\text { occlusion }\end{array}$} & \multicolumn{2}{|c|}{ Currently } \\
\hline & Mean & SD & Mean & SD & Mean & SD \\
\hline $\begin{array}{l}\text { Acuity fellow eye } \\
\text { (logMAR) }\end{array}$ & & & & & 0.1 & 0.1 \\
\hline $\begin{array}{l}\text { Acuity amblyopic eye } \\
\text { (logMAR) }\end{array}$ & 0.6 & 0.3 & 0.3 & 0.3 & 0.3 & 0.4 \\
\hline $\begin{array}{l}\text { Anisometropia } \\
\text { (Diopters) }\end{array}$ & 0.7 & 1.0 & & & 1.2 & 1.5 \\
\hline
\end{tabular}

had secondary education and higher education and university (Table 1).

\section{Orthoptic data}

The mean acuity of the amblyopic eye had improved by the occlusion therapy and remained at approximately the same level during the subsequent 30 years (Table 2).

The degree of binocular vision of the 137 patients had slightly improved during the 30 years between the end of the occlusion therapy and re-examination, as shown by the distribution of patients on the categories of binocular vision (Fig. 3).

The most frequent types of the current strabismus of the 137 patients were microstrabismus and infantile esotropia (Table 3). The strabismus types were defined as follows: infantile esotropia as manifest esotropia with onset between birth and 6 months; exotropia as manifest diverging of visual axes; microstrabismus as strabismus with angle of deviation $0.5^{\circ}-5^{\circ}$ with reduced binocular vision; small angle as strabismus with angle of deviation $5^{\circ}-12^{\circ}$ with reduced binocular vision; subnormal binocular vision as orthotropia with reduced binocular vision; intermittent exotropia as occasionally manifest exotropia. In addition to strabismus, several patients had other strabismus-related problems, like latent nystagmus and DVD.

Correlations between quality of life and orthoptic parameters

The correlations between the A\&SQ domains and continuous past (1968-1975) and current (2002-2003) orthoptic parameters were performed by $(r)$ Pearson correlation test and between domains and dichotomous parameters by mean score difference (delta). The two-tailed levels of

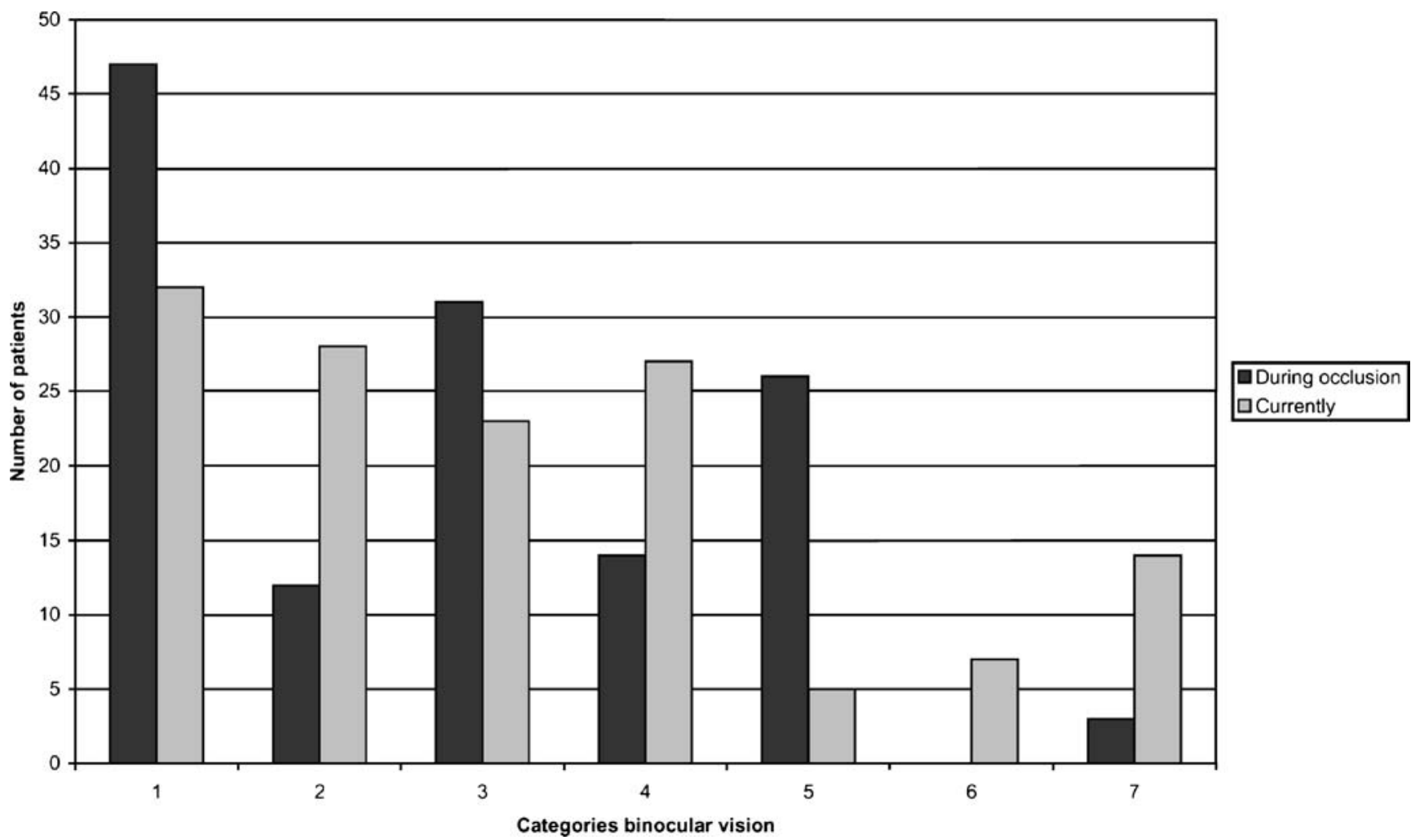

Fig. 3 Binocular vision of the 137 patients is indicated during occlusion, 30-35 years ago (black bars), and current re-examination (gray bars). The degree of binocular vision was divided into seven categories based on tests for binocular vision and for stereopsis (from worst to best on abscissa). 1: Bagolini negative; 2: Bagolini positive;
3: Bagolini and Titmus stereotest fly positive; 4: minimal Titmus stereotest circles $200^{\prime \prime}-140 "$ positive; 5: minimal Titmus stereotest circles 100"-40" positive; 6: Lang stereotest or minimal TNO test Plate V positive; 7: TNO test Plate VI or VII. Number of patients is represented on ordinate 
Table 3 Patients per condition

\begin{tabular}{ll}
\hline Current condition & $N$ \\
\hline Infantile esotropia & 26 \\
Exotropia & 8 \\
Microstrabismus & 60 \\
Small angle strabismus & 5 \\
Subnormal binocular & 5 \\
Intermittent exotropia & 7 \\
Latent nystagmus & 40 \\
Nasal fixation & 44 \\
DVD & 20
\end{tabular}

Note: Patients could fall in more than one category of condition.

significance were $* *(P<0.01)$ and $*(P=0.01-P=0.05$ (Table 4).

The domain "fear of losing the better eye" was significantly correlated $(P<0.01)$ to the current acuity at distance of the amblyopic eye and DRT results of the amblyopic eye (Table 4).

The domain "distance estimation" was significantly correlated $(P<0.01)$ to the current acuity at distance of the amblyopic eye and DRT results of the amblyopic eye, and degree of binocular vision.

The domain "visual disorientation" was significantly correlated $(P<0.01)$ to the current acuity at distance of the amblyopic eye.
The domain "diplopia" was significantly correlated $(P<$ $0.01)$ to the current DRT results of the amblyopic eye.

The domain "social contact and cosmetic problems" was significantly correlated $(P<0.01)$ to the current DRT results of the amblyopic eye, and the degree of binocular vision.

The current acuity at distance of the amblyopic eye correlated at the level of significance $P<0.01$ to three of the five A\&SQ domains. The DRT results of the amblyopic eye correlated at the level of significance $P<0.01$ to four of the five A\&SQ domains. The current degree of binocular vision correlated at the level of significance $P<0.01$ to two of the five A\&SQ domains. None of the other correlations were significant at the levels of $P<0.01$ and $P=0.01-\mathrm{P} 0.05$.

\section{Discussion}

It was surprising that the current acuity at distance of the amblyopic eye and the current DRT results of the amblyopic eye proved to be overall dominant $(P=0.01-$ $P$ 0.05) for all five A\&SQ domains: "fear of losing the better eye", "distance estimation", "visual disorientation", "diplopia", and "social contact and cosmetic problems". On the one hand, the deficit of an amblyopic eye in itself may have profuse effects on vision. On the other hand,

Table 4 Past and current orthoptic parameters correlated to the five A\&SQ domains

\begin{tabular}{|c|c|c|c|c|c|c|c|c|c|c|}
\hline \multirow{3}{*}{$\begin{array}{l}\text { Examined orthoptic } \\
\text { parameters } \\
1968-1975\end{array}$} & \multicolumn{10}{|c|}{ Five domains of the A\&SQ } \\
\hline & \multicolumn{2}{|c|}{$\begin{array}{l}\text { Fear losing better } \\
\text { eye }\end{array}$} & \multicolumn{2}{|c|}{ Distance estimation } & \multicolumn{2}{|c|}{$\begin{array}{l}\text { Visual } \\
\text { disorientation }\end{array}$} & \multicolumn{2}{|l|}{ Diplopia } & \multicolumn{2}{|c|}{ Contact\&cosmetic } \\
\hline & $\begin{array}{l}r \text { or } \\
\text { delta* }\end{array}$ & $P^{* *}$ & $\begin{array}{l}r \text { or } \\
\text { delta* }\end{array}$ & $P^{* *}$ & $\begin{array}{l}r \text { or } \\
\text { delta* }\end{array}$ & $P^{* *}$ & $\begin{array}{l}r \text { or } \\
\text { delta* }\end{array}$ & $P^{* *}$ & $\begin{array}{l}r \text { or } \\
\text { delta* }\end{array}$ & $P^{* *}$ \\
\hline $\begin{array}{l}\text { Acuity amblyopic eye } \\
\text { (start occl.) }\end{array}$ & -0.178 & $0.038^{*}$ & -0.236 & $0.013^{*}$ & -0.078 & 0.385 & -0.131 & 0.129 & -0.226 & $0.008^{*}$ \\
\hline $\begin{array}{l}\text { Acuity amblyopic eye } \\
\text { (end occl.) }\end{array}$ & -0.301 & $0.000 * *$ & -0.369 & $0.000 * *$ & -0.187 & $0.036^{*}$ & -0.080 & 0.356 & -0.166 & 0.053 \\
\hline \multicolumn{11}{|l|}{2003} \\
\hline Acuity amblyopic eye & -0.479 & $0.000 * *$ & -0.460 & $0.000 * *$ & -0.290 & $0.001 * *$ & -0.201 & $0.019^{*}$ & -0.216 & $0.011 *$ \\
\hline Dutch Reading Test & -0.437 & $0.000^{* *}$ & -0.439 & $0.000 * *$ & -0.206 & $0.020 *$ & -0.251 & $0.003 * *$ & -0.235 & $0.006^{* *}$ \\
\hline Binocular vision & -0.188 & $0.028^{*}$ & -0.316 & $0.001 * *$ & -0.142 & 0.111 & -0.179 & $0.037^{*}$ & -0.298 & $0.000^{* *}$ \\
\hline Nasal fixation & $10.5^{*}$ & 0.085 & $5.4^{*}$ & 0.105 & $-1.9 *$ & 0.553 & $6.7^{*}$ & 0.166 & $0.8^{*}$ & 0.876 \\
\hline Angle of strabismus & 0.074 & 0.389 & 0.009 & 0.922 & 0.099 & 0.266 & -0.010 & 0.912 & -0.087 & 0.311 \\
\hline Latent nystagmus & $5.1^{*}$ & 0.395 & $-1.8 *$ & 0.591 & $2.3^{*}$ & 0.464 & $-2.9 *$ & 0.464 & $11.6^{*}$ & 0.013 \\
\hline Anisometropia & $18.8^{*}$ & 0.085 & $-0.1^{*}$ & 0.990 & $1.3^{*}$ & 0.773 & $1.9^{*}$ & 0.527 & $-9.6^{*}$ & 0.207 \\
\hline
\end{tabular}

$r$ or delta*: Pearson correlation (two-tailed) of the continuous orthoptic parameters with the A\&SQ domains/mean score difference for correlation between dichotomous orthoptic parameters and A\&SQ domains (if situation is present)

$P^{* *}$ : Level of significance for correlations between continuous orthoptic parameters and the A\&SQ domains or for unpaired t-test between dichotomous parameters and the A\&SQ domains

Levels of significance (two-tailed): $P^{*}=0.01-0.05 ; P^{* *}<0.01$

Note: The current acuity of the amblyopic eye, measured at distance and by the DRT, were the most significantly correlated parameters to all of the five A\&SQ domains. 
intermediate factors could cause the effect-i.e. dominance of the adult visual acuity of the amblyopic eye on the A\&SQ domains-but that these factors could not be detected by either the questions of the A\&SQ or the tests used in the orthoptic examinations. Thirdly, development of the brain, especially at higher cortical levels, may affect together visual acuity, distance estimation and visual disorientation.

The correlation of the domain "distance estimation" to both acuity and degree of binocular vision may suggest that both are limiting factors in final reaching to and grasping of objects (prehension) [9]. The domain "visual disorientation" may be functionally analogous to positional uncertainty [10] and thus possibly be influenced by the acuity of the amblyopic eye. There is, to our knowledge, no prior research that might explain the correlation of the domain "social contact and cosmetic problems" with latent nystagmus. It is not known to what extent the latent nystagmus became manifest in daily life in the patients, something that could explain the correlation.

Our historic cohort showed a higher proportion of occluded children $(4.8 \%)$ than the prevalence of amblyopia, determined as unilateral visual impairment in adulthood, in a population not treated for amblyopia (3.25\%) [8]. This discrepancy can be explained by the tendency of orthoptists to overtreat a child's amblyopia after screening: It is not known beforehand which cases of amblyopia will improve or deteriorate spontaneously between end of treatment and adulthood [11]. Orthoptists will therefore tend to prescribe occlusion therapy even in cases of mild amblyopia.

Considering the overall dominance of the current acuity of the amblyopic eye, our results emphasize the necessity of effective treatment of amblyopia.
Acknowledgements This study was financially supported by the Foundation Ondersteuning Oogheelkunde 's-Gravenhage, Foundation Blindenhulp and the Ooglijders Foundation.

We thank the Waterland Hospital in Purmerend for their hospitality and the orthoptists J.R. Polling and H.M. van Minderhout for their involvement.

\section{References}

1. Jensen B, Goldschmidt E (1986) Visual acuity in Danish school children. Acta Ophthalmol 64:187-191

2. Rahi JS, Cumberland PM, Peckham CS (2006) Does amblyopia affect educational, health, and social outcomes? Findings from 1958 British birth cohort. BMJ 332:820-825

3. Mangione CM et al (1998) Identifying the content area for the 51item National Eye Institute Visual Function Questionnaire. Results from focus groups with visually impaired persons. Arch Ophthalmol 116:227-233

4. Dutch consensus translation VFQ-25/NL (URL: http://www2.eur. $\mathrm{nl} / \mathrm{fgg} / \mathrm{mgz} /$ publications.papers)

5. van de Graaf ES et al (2004) Amblyopia and Strabismus Questionnaire: design and initial validation. Strabismus 12:181193

6. Felius J et al (2007) The Amblyopia and Strabismus Questionnaire: english translation, validation, and subscales. Am J Ophthalmol 143:305-310

7. van de Graaf ES et al (2005) Factor-analysis of the Amblyopia and Strabismus Questionnaire (A\&SQ). Ann Meet Abstr Progr Planner http://www.arvo.org). Assoc Res Vision \& Ophthalmol, Abstract 5705

8. Attebo K et al (1998) Prevalence and causes of amblyopia in an adult population. Ophthalmology 105:154-159

9. Grant S et al (2007) Prehension deficits in amblyopia. IOVS 48:1139-1148

10. Mansouri B et al (2004) Integration of orientation information in amblyopia. Vis Res 44:2955-2969

11. Simonsz-Toth B et al (2007) Visusevaluiering in einer historischen Kohorte von 137 okkludierten Patienten, 30-35 Jahre nach Ende der Okklusionsbehandlung (Evaluation of visual acuity in a historic cohort of 137 patients treated for amblyopia by occlusion 30-35 years ago). Klin Monatsbl Augenheilkd 224:40-46 